\title{
Las salas multiconfesionales en el contexto hospitalario catalán: negociaciones y tensiones en la gestión de la diversidad
}

\author{
Multifaith rooms in the Catalan hospital context: \\ negotiations and tensions in the management of \\ religious diversity
}

Anna Clot-Garrell'1 , Mar Griera²

${ }^{1}$ Doctora en Sociología. Investigadora postdoctoral, Universitat Autònoma de Barcelona, Barcelona, España. $\triangle$ iD

${ }^{2}$ Doctora en Sociología. Profesora, Departamento de Sociología, Universitat Autònoma de Barcelona, Barcelona, España. $\bowtie$ iD
RESUMEN Las salas multiconfesionales son un modelo emergente de gestión y acomodación de la diversidad religiosa que prolifera en el ámbito sanitario. Este artículo se centra en la micropolítica implicada en el diseño de estos espacios multireligiosos en el contexto hospitalario. Partiendo de la evidencia empírica reciente y del "giro material" en el estudio de la religión, ponemos el acento en estudiar las negociaciones materiales que subyacen en la creación de estos espacios religiosos. El artículo se basa en un estudio etnográfico desarrollado entre 2013 y 2016, con una estrategia de casos múltiple (tres hospitales) en el contexto catalán. Se realizaron doce entrevistas en profundidad a líderes religiosos de diferentes confesiones, a trabajadores y personal directivo del hospital, y observaciones en las salas multiconfesionales. Se concluye que los espacios multiconfesionales no son conciliadores ni integradores per se, sino más bien contextos de tensión y contestación. Una dimensión, por tanto, conflictual inherente a la naturaleza de este tipo de espacios que debe reconocerse e integrarse en la gestión de la diversidad en el contexto hospitalario.

PALABRAS CLAVES Diversidad Cultural; Religión; Espiritualidad; Hospitales.

\begin{abstract}
Multifaith rooms are an emerging model for the management and accommodation of the religious diversity that proliferates in the health field. This article examines the micropolitics of the design of multireligious spaces in hospital contexts. Drawing on recent empirical evidence and the "material turn" in the study of religion, we focus on the material negotiations that underlie the creation of these religious spaces. The article is based on an ethnographic study carried out between 2013 and 2016 using the strategy of a multiple case study (in three hospitals) in Catalan. Twelve in-depth interviews with religious leaders of different faiths and hospital staff and managers, as well as observations in multifaith spaces, were carried out. The article shows that multifaith rooms are not conciliatory and integrative per se, but rather constitute contexts of tension and contention. We conclude that an inherent conflictual dimension is part of the nature of this type of spaces and should be recognized and integrated into the management of diversity in hospital contexts.
\end{abstract}

KEY WORDS Cultural Diversity; Religion; Spirituality; Hospitals. 


\section{INTRODUCCIÓN}

Las salas multiconfesionales son cada vez más una realidad en instituciones públicas de todo el mundo ${ }^{(1,2,3,4,5,6,7,8,9)}$. Hospitales, prisiones, aeropuertos, universidades e incluso centros comerciales o campos de futbol implementan este modelo espacial de reconocimiento simbólico y de acomodación práctica de la diversidad religiosa. Las salas multiconfesionales son definidas como "espacios sagrados universales" diseñados para acomodar en un mismo lugar diferentes confesiones religiosas, formas de espiritualidad e incluso expresiones de trascendencia sin ninguna vinculación con tradiciones religiosas y/o espirituales ${ }^{(10)}$. Las soluciones para dar respuesta a esta ecléctica funcionalidad han dado lugar a diferentes diseños que pueden ir desde la creación de un espacio minimalista al uso de diferentes símbolos religiosos y espirituales. Más allá de sus formas experimentales, los espacios multiconfesionales también se han convertido en una prioridad a nivel político. El Consejo de Europa, por ejemplo, ha incluido las salas religiosas multiconfesionales en instituciones públicas como una recomendación política para acomodar a las minorías, principalmente musulmanes, y combatir la discriminación ${ }^{(11)}$. Las salas multiconfesionales son, por consiguiente, un fenómeno en expansión internacional. Este artículo se centra en analizar el surgimiento de las salas multiconfesionales en el contexto hospitalario catalán.

En España, los espacios multiconfesionales son un fenómeno creciente pero relativamente nuevo y, en buena medida, todavía son una excepción más que la norma. Así, puede constatarse que la mayoría de los hospitales mantienen una capilla tradicional como herencia del pasado monoconfesional católico y del rol que ha jugado la Iglesia en el ámbito sanitario. Sin embargo, observamos una nueva tendencia en los hospitales de reciente construcción o que han renovado sus instalaciones en los últimos tiempos. En la mayoría de estos casos, la construcción de un nuevo edificio ha supuesto la creación de una sala multiconfesional que reemplaza la antigua capilla católica. Son casos limitados, pero una novedad significativa y en expansión. Sin embargo, y a pesar de la voluntad de inclusión, igualdad y neutralidad que ha representado la creación de estos espacios, las nuevas salas multiconfesionales son en la actualidad, escasamente demandadas y utilizadas por los diferentes grupos religiosos, más concretamente por aquellas minorías religiosas para las que fueron diseñadas.

Este artículo toma el fenómeno de las salas multiconfesionales como objeto de estudio y examina críticamente este modelo emergente de gestión de la diversidad religiosa en el ámbito sanitario catalán. Hasta ahora el estudio de las salas multiconfesionales se ha desarrollado principalmente desde una perspectiva legal e icónica que ha promovido estos espacios y ha dedicado poca atención a examinar cómo los principios de la diversidad y la neutralidad se traducen en la práctica y en el uso real de estos espacios. Sin embargo, tal y como muestra la evidencia empírica reciente, el "éxito" y buen funcionamiento de estos espacios no puede darse por supuesto. Por esta razón, en este artículo desarrollamos un análisis de la micropolítica implicada en la formulación y diseño de estas salas multiconfesionales para ahondar en las razones que explican por qué su implementación no ha respondido a las expectativas iniciales en términos del uso y apropiación por parte de las minorías religiosas. A su vez, relatamos cómo la creación de estas salas ha generado consecuencias no previstas, como la generación de espacios de uso espiritual individual para la meditación o la reflexión silenciosa.

Partimos de una concepción de los espacios religiosos en las instituciones públicas como espacios políticos ${ }^{(12)}$. Espacios que permiten examinar cómo las luchas políticas toman forma de luchas simbólicas ${ }^{(13)}$. Por consiguiente, ponemos el acento en estudiar las negociaciones materiales que tienen lugar en la creación y el diseño de estos espacios religiosos en el contexto hospitalario. La atención a la dimensión material ${ }^{(14)}$, más que a la normativa que ha guiado tradicionalmente 
la aproximación a las políticas del diseño de estos espacios, permite observar cómo las relaciones de poder entre grupos religiosos y seculares que subyacen en la vida cotidiana de la institución cristalizan simbólicamente en términos de artefactos y discursos materiales en estos espacios multiconfesionales.

\section{ACERCA DE LA INVESTIGACIÓN}

Este artículo surge de un proyecto de investigación sobre la diversidad religiosa en las instituciones públicas en España (20102014). El proyecto, basado en una comparación entre prisiones y hospitales de dos regiones españolas (Andalucía y Cataluña), tuvo como objetivo analizar los procesos de gestión y acomodación de las minorías religiosas y el papel cambiante de la Iglesia católica en un escenario secular y plural. Los resultados presentados en este artículo se derivan de la investigación llevada a cabo en el contexto catalán. El análisis toma como muestra el caso de tres hospitales que, en el mismo período (primera década del segundo milenio) y territorio (Cataluña), Ilevaron a cabo la creación de espacios religiosos multiconfesionales en el transcurso de la renovación del antiguo edificio y la construcción de uno nuevo. El punto común de estos tres hospitales es, por una parte, el hecho de ser pioneros en implementar este modelo multiconfesional atento a la diversidad $y$, por otra, las consecuencias no deseadas de este tipo de acomodación. Y es que, a pesar de los esfuerzos de inclusión e igualdad en la creación de estos nuevos espacios religiosos, la realidad actual es que son espacios controvertidos e infrautilizados donde nadie parece sentirse a gusto, ni las minorías religiosas, ni la Iglesia católica ni, a veces, tan siquiera el propio personal sanitario.

En este artículo desarrollamos un análisis crítico de este nuevo proceso que, en el contexto español, representa la creación de espacios multiconfesionales en los hospitales. Los resultados examinados son fruto de un diseño de estudio de casos múltiple y un enfoque metodológico cualitativo de tipo etnográfico. La investigación consistió en dos fases: a) una primera fase exploratoria, entre 2013 y 2014, en la que visitamos diferentes hospitales y salas de oración para identificar los casos; b) un trabajo de campo intensivo, entre 2014 y el 2016, en el que seleccionamos los casos y realizamos el trabajo de campo específico. Concretamente, se llevaron a cabo 12 entrevistas en profundidad a líderes religiosos de diferentes confesiones religiosas presentes en el ámbito sanitario (catolicismo, cristianismo evangélico, islam) y personal del hospital. La selección de los entrevistados se realizó siguiendo criterios de relevancia para el caso de estudio, así como de acceso y disponibilidad. Por una parte, se entrevistaron los líderes religiosos autorizados por el centro hospitalario para ofrecer asistencia religiosa, así como los líderes religiosos que organizan, dentro de la propia confesión, la asistencia religiosa en el sistema hospitalario catalán. Asimismo, en el caso del personal sanitario, se entrevistaron diferentes perfiles de acuerdo con las recomendaciones de cada hospital.

En el caso 1 se entrevistó al director de atención al cliente del hospital y la enfermera que gestiona la asistencia religiosa entre los pacientes; en el caso 2 se entrevistó a la responsable de atención al cliente y la presidenta del comité de ética; $y$, en el caso 3, se entrevistó a los encargados laicos del servicio religioso del hospital. Todas las entrevistas se registraron mediante grabación de audio y fueron transcritas en forma íntegra. Paralelamente, se llevaron a cabo en cada hospital observaciones en salas multiconfesionales que se registraron mediante notas de campo siguiendo pautas de observación y fotografías. Finalmente, también se consultaron documentos oficiales de hospitales en relación con la regulación de estos espacios. Todo el material fue procesado y analizado combinando técnicas de análisis de contenido, temático y narrativo(15).

Finalmente, es preciso explicitar que el proyecto fue aprobado por el Comité de Ética de la Universitat Autònoma de Barcelona. Durante el trabajo se han contemplado 
las cuestiones éticas siguiendo la normativa y el asesoramiento del Comité de Ética de la universidad. Al inicio de la investigación, se presentó el proyecto a los hospitales seleccionados y se solicitó su consentimiento para acceder y llevar a cabo este estudio con una finalidad estricta y exclusivamente académica. Respecto de los informantes, en todo momento se les ha informado el propósito estrictamente académico de la investigación y se ha garantizado el máximo respeto, así como la confidencialidad. En este sentido, el tratamiento y sistematización de los datos se ha llevado a cabo con mucho rigor y se ha garantizado en todo momento su anonimato. Por esta razón, cualquier nombre que aparece en este artículo es ficticio con el fin de preservar la confidencialidad y anonimato.

El artículo se estructura en cinco partes. Una primera, donde se exponen las características y transformaciones más relevantes del contexto religioso y la implicación de la Iglesia católica y las minorías religiosas en el contexto de la institución pública hospitalaria. En una segunda parte se introduce la perspectiva teórica que guía la aproximación empírica del estudio de la religión en el ámbito sanitario a partir del análisis de las salas multiconfesionales. En tercer lugar, se desarrolla una descripción analítica de los casos de estudio para finalizar con la discusión de los resultados presentados y la conclusión.

\section{CATOLICISMO, SECULARIZACIÓN Y DIVERSIDAD RELIGIOSA}

En las últimas décadas, el paisaje religioso español ha experimentado cambios importantes. Por una parte, desde fines de la década de 1970, la Iglesia católica ha atenuado su posición dominante en la sociedad, si bien ha mantenido un "estatus especial" en una España que fue declarada como país "aconfesional". Los acuerdos entre el Vaticano y el Gobierno español, firmados poco después de la aprobación de la Constitución española de 1978, regulan el papel de la Iglesia católica en el país y en entornos institucionales específicos, dotando de una constante presencia de la Iglesia en ciertos ámbitos sociales. Por ejemplo, en el contexto hospitalario, los temas más relevantes que regulan los acuerdos son el número de capellanes católicos por cada hospital según el número de camas y el costo de la pastoral católica, que incluye el sueldo de los capellanes que el gobierno debe cubrir. Además, los acuerdos especifican que los hospitales están obligados a tener una capilla católica y a proporcionar una habitación y una oficina a los capellanes.

Por otra parte, ha tenido lugar también una consolidación del proceso de secularización. La separación política entre el Estado y la Iglesia ha ido desembocando en una caída drástica de la asistencia religiosa ${ }^{(16,17)}$ y de las tasas de identificación religiosa ${ }^{(18)}$, especialmente en Cataluña. La democracia se unió a una concepción de la modernidad secular que puso a la religión como perteneciente al pasado ${ }^{(19)}$. Las elites seculares ${ }^{(20)}$ ganaron poder y visibilidad en la esfera pública ${ }^{21,22}$ y la batalla histórica entre las facciones secularistas y antisecularistas perdió su impulso. Hoy en día, la oposición entre lo religioso y lo secular ha cambiado significativamente, aunque todavía no hay consenso sobre el lugar que debe ocupar la religión -y especialmente la Iglesia católica- en las instituciones públicas y, por extensión, en la sociedad.

Paralelamente, también en los últimos años ha tenido lugar un proceso de pluralización. El mapa religioso español se ha ido diversificando como resultado de las olas migratorias de las últimas dos décadas ${ }^{(23,24,25,26)}$. Entre 2000 y 2009, la población no nacida en España se cuadriplicó, pasando de menos de 1,5 millones a más de 6,5 millones ${ }^{(27)}$, lo que favoreció un crecimiento sustancial de las minorías religiosas ya que la llegada de personas procedentes de países con gran presencia de tradiciones religiosas no católicas provocó un aumento sustancial de fieles y la apertura de nuevos centros religiosos. En los datos disponibles a nivel estatal, facilitados por la Fundación Pluralismo y Convivencia, en el año 2016, se contabilizaron 6.814 centros de culto no católicos en España, siendo Cataluña la comunidad autónoma con un 
mayor número de centros de culto. De acuerdo con los últimos datos actualizados por el mapa de las religiones, provistos por el grupo Investigaciones en Sociología de la Religión (ISOR) y la Dirección General de Asuntos Religiosos de la Generalitat de Cataluña, en 2014 se contabilizaron 1.360 lugares de culto no católicos. La mayoría (725) pertenecen a iglesias evangélicas. El islam es la segunda confesión religiosa representada, con un total de 256 oratorios, seguidas por las 118 salas del reino de los testigos cristianos de Jehová. A cierta distancia, encontramos 68 centros budistas, 55 iglesias orientales, 24 iglesias adventistas del séptimo día, 15 iglesias mormonas, 27 centros hinduistas, 10 del sijismo, 9 de la fe bahà'í, 6 del taoísmo y 4 del judaísmo. En la evolución de estos centros de culto, se observa el impacto de las migraciones. Por ejemplo, en el caso de las minorías religiosas más mayoritarias, observamos que el cristianismo evangélico contabiliza más de 94 regiones geográficas diferentes de procedencia de la mayoría de los miembros y, en el caso del islam, 17 regiones geográficas.

No obstante, el reconocimiento legal de esta diversidad se ha traducido en una lógica asimétrica en los procesos de acomodación religiosa. El ordenamiento jurídico garantiza el derecho a la libertad religiosa y de conciencia de toda la ciudadanía, pero el sistema de reconocimiento y protección legal de los derechos varía en función del grupo al que se pertenece. Existen cuatro niveles diferentes de reconocimiento que, articulados a partir de instrumentos jurídicos diferenciados, atribuyen diferentes grados de protección a los derechos individuales y colectivos en materia religiosa. El primer nivel de reconocimiento es el que garantizan los acuerdos concordatarios con rango de tratado internacional, firmados en 1979 con la Iglesia católica. Un segundo nivel de reconocimiento es el garantizado por los acuerdos de cooperación de 1992, con rango de Ley Orgánica, para las confesiones con un arraigo histórico en el país: el protestantismo, judaísmo e islam. Un tercer nivel de reconocimiento jurídico es el del notorio arraigo de la iglesia de Jesucristo de los santos de los últimos días en 2004, los testigos de Jehová en 2006, el budismo en 2007, y la iglesia ortodoxa en 2010. Finalmente, un cuarto nivel de reconocimiento para el resto de confesiones religiosas tales como el hinduismo, taoísmo, entre otras, en el Registro de Entidades Religiosas.

A nivel práctico, las diferencias existentes son especialmente evidentes al comparar la situación de la iglesia católica con la de las demás confesiones en el ámbito de las instituciones públicas, tal y como se ha detallado previamente. Sin embargo, la creciente relevancia y visibilidad de la diversidad religiosa, también ha obligado a la Iglesia católica a replantear sus estrategias de acción y visibilidad $^{(28,29)}$. En este contexto de cambios rápidos, la gestión de la diversidad religiosa y cultural está ganando terreno y es incorporada en la agenda política del gobierno en todos sus niveles ${ }^{(30)}$. En este sentido, el análisis de las formas en que estas transformaciones impactan y se cristalizan en las instituciones públicas como los hospitales es una cuestión central de estudio para examinar el resurgimiento de la religión en el espacio público y la articulación de las nociones liberales de neutralidad respecto a la religión en contextos seculares como es el sanitario.

\section{Religión, contexto hospitalario y espacios multiconfesionales}

Son diferentes las investigaciones que han comenzado a abordar cómo se configura la compleja relación entre minorías religiosas, iglesias históricas e instituciones públicas en un paisaje religioso marcado por la consolidación del proceso de secularización y la pluralización religiosa descrita. Wendy Cadge ${ }^{(2)}$, en su estudio del contexto hospitalario estadounidense, ha subrayado la importancia de examinar el papel y las transformaciones de la religión, más allá del ámbito de lo que se conoce como "estudios congregacionales" y la vida religiosa de los creyentes en las instituciones religiosas tradicionales. Cadge sostiene que examinar el papel de la religión en contextos seculares permite analizar el proceso de reconfiguración de la relación entre 
lo secular y lo religioso en la esfera pública contemporánea y hacer inteligible cómo estas transformaciones toman forma en entornos institucionales particulares como el ámbito sanitario. En esta misma línea, tal y como señalan James Beckford y Sophie Gilliat-Ray, las instituciones públicas son contextos privilegiados y estratégicos de estudio, ya que representan sitios en los que "los desafíos políticos, los conflictos y las negociaciones de una sociedad multicultural son susceptibles de ser observados en miniatura" [traducción del original: "the political challenges, conflicts and negotiations of a multicultural society can be observed in miniature, as it were" $]^{(31)}$.

Partiendo de esta literatura, en este artículo nos centramos en los hospitales catalanes para examinar las transformaciones de los espacios religiosos dentro de esta institución pública y secular particular. De acuerdo con Alice Street y Simon Coleman, concebimos los hospitales como espacios con un estatus paradójico, a la vez cerrados y permeables a las dinámicas y procesos sociales; contextos institucionales en los que coexisten, simultáneamente, múltiples ordenamientos espaciales, biomédicos y no biomédicos. Los espacios destinados a las cuestiones religiosas en los hospitales son parte de esta realidad compleja de "condensaciones materiales de espacios múltiples, contradictorios y controvertidos" [traducción del original: "material condensation of multiple spaces, which are both contradictory and contested" $]^{(32)}$. Por consiguiente, las salas multiconfesionales son contextos de investigación particularmente pertinentes para examinar las tensiones y negociaciones que subyacen a la gestión de la diversidad religiosa en este tipo de institución pública.

En España, el análisis de los nuevos espacios multiconfesionales en las instituciones públicas, destinados a ampliar los servicios de asistencia religiosa cada vez más sensibles a un escenario de creciente diversidad religiosa, se ha desarrollado, principalmente, desde perspectivas normativas y legales. Estos trabajos se han centrado en lo que "debería ser", de acuerdo con la Ley de Libertad
Religiosa de $1980^{(33,34)}$, pero no han examinado las dinámicas cotidianas que tienen lugar en el contexto material concreto de las salas multiconfesionales en las instituciones sanitarias. Este artículo adopta, por el contrario, un enfoque etnográfico de las políticas de diseño de los espacios multiconfesionales con el fin de capturar las tensiones y negociaciones imbricadas en su proceso de creación, en la aplicación de la normativa en contextos específicos y en sus usos reales. $Y$ es que, de acuerdo con las investigaciones empíricas recientes, el "éxito" de estos espacios no puede darse por supuesto por la simple regulación de su existencia bajo el amparo de la Ley de Libertad Religiosa.

Sophie Gilliat-Ray ${ }^{(12)}$, por ejemplo, en su investigación en el Reino Unido, ha mostrado cómo la construcción de salas multiconfesionales puede favorecer y hacer cristalizar luchas políticas, particularmente, con relación a cuestiones de propiedad, apropiación y diseño. Asimismo, Emerson Giumbelli ${ }^{(7)}$, en su análisis de la construcción de salas multiconfesionales en el contexto brasileño, explica cómo las diferentes concepciones de lo religioso y lo secular compiten en la formulación y el diseño de estos espacios socavando su deseada y reivindicada inclusividad. Y no es solamente que el proceso de creación de estos espacios se convierta en un escenario de luchas de poder, sino también que no hay evidencia empírica clara sobre su capacidad real para satisfacer las necesidades religiosas de los usuarios. En algunos casos, las salas multiconfesionales se convierten en espacios vacíos mientras que, en otros, una sola confesión religiosa es la que se apropia del lugar ${ }^{(1,3,30,35)}$.

Partiendo de esta evidencia empírica y del "giro material" en el estudio de la religión ${ }^{(36,37,38)}$, ponemos el acento en estudiar las negociaciones materiales que subyacen en la creación y el diseño de estos espacios religiosos. Es decir, identificar cómo la idea de "multiconfesionalidad" se traduce en términos materiales en la creación y diseño de estos espacios religiosos innovadores. Analizamos, por tanto, los procesos de gestión de los recursos simbólicos involucrados en la política de diseño de los espacios multiconfesionales; las 
narrativas y prácticas de los actores institucionales y religiosos en torno a la materialidad de estos espacios ya que, tal y como afirma Guy Julier, "los objetos y los discursos son mutuamente dependientes en generar pertenencia" [traducción del original: "Design objects and discourse are mutually dependent in generating belonging" $]^{(39)}$.

\section{Resultados empíricos}

\section{Caso 1: La diversidad es vacío}

Llegamos a un hospital recién inaugurado y situado a las afueras de una ciudad cercana a Barcelona. No encontramos ninguna indicación de dónde se encuentra la Ilamada "sala de reflexión" que, según indica la página web del hospital, "cualquier usuario puede utilizar para orar, meditar o hacer ejercicios espirituales". El servicio de atención al cliente nos confirma la existencia de este espacio y nos indica una pequeña habitación situada al final del piso principal del edificio. La administrativa señala que la habitación está vacía; es lo más neutral posible para ser adecuada a todos los usuarios, aunque también nos explica que los usuarios suelen pedir una "capilla".

Nos dirigimos hacia este llamado "espacio de reflexión" y llegamos a una pequeña habitación con puerta entreabierta que se denomina "servicio religioso". Junto a la puerta de la habitación, observamos un pequeño cartel en el que se especifican los horarios de atención religiosa católica y la celebración de la misa semanal. Entramos en esta habitación estrecha con paredes blancas sin ningún diseño aparente y arquitectura particular. El elemento más visible es un cartel relativamente grande de la cúpula de una catedral católica. Un pequeño altar de madera con ruedas, una cruz, un armario cerrado con una imagen de una iglesia rural católica en la parte superior y dos bancos de madera con capacidad para unas doce personas marcan la distribución del espacio. En los bancos observamos también folletos católicos de oraciones y misiones.
El antiguo hospital tenía una capilla católica tradicional pero, al construir el edificio nuevo, la gerencia del hospital pensó en crear un espacio multiconfesional asignando una habitación vacía del hospital con este propósito. En este sentido, uno de los directivos del hospital nos explicaba que el hecho de que no es arquitectónicamente una capiIla, refleja el tipo de concepción que tiene la dirección del hospital. La creación de la sala multiconfesional fue una decisión de la dirección enmarcada como un servicio que quería responder a la "visión integradora" del hospital con relación a la salud. Tal y como nos explicaba el directivo del hospital, esta visión contemplaba una vertiente espiritual que cubrían a través del servicio de asistencia religiosa y esta nueva sala multiconfesional. Sin embargo, la creación de este espacio no implicó la definición de una política del hospital respecto a los asuntos religiosos ni se siguió ninguna directriz específica del gobierno catalán que actualmente dispone de unas guías de "respeto y atención a la diversidad religiosa en el ámbito sanitario". La dirección del hospital simplemente destinó una sala vacía para cumplir con este servicio y responder a futuras demandas de las minorías religiosas. En este sentido, es interesante destacar que la idea de la "sala de reflexión" no surgió como consecuencia de peticiones concretas o necesidades reales de los usuarios, sino como fruto de una concepción abstracta de la diversidad. Según el personal del hospital, la diversidad religiosa es escasamente visible y poco problemática entre los pacientes, excepto en el caso de situaciones particulares y muy ocasionales con pacientes musulmanes. Por consiguiente, la sala no era concebida como una solución a un problema específico sino como una práctica destinada a promulgar la "modernidad" del nuevo hospital en términos de un proyecto secular y plural. El hospital adoptó, así, una gestión de la diversidad religiosa del laissez faire, presuponiendo que tan solo dedicando una sala a este fin se daría una relación libre y conciliadora entre los grupos religiosos.

Desde la inauguración del hospital, no se ha registrado ninguna demanda de ningún 
grupo religioso minoritario por lo que respecta al uso de la sala. Sin embargo, pocos meses después de la inauguración del espacio multiconfesional, el obispo católico de la zona mostró su descontento con la nueva sala religiosa. Sus quejas las fundamentó en los acuerdos entre la Iglesia católica y el Estado español alegando que, según el concordato, cada hospital tiene que tener una "capilla". Desde su propia concepción, la "sala de reflexión" no podía sustituir una capilla católica propiamente dicha. El hospital decidió no enfrentarse a la Iglesia católica y promovieron la firma de un acuerdo especial entre el hospital y el obispo que, según uno de los directores del hospital, implicaba una "evolución del espacio multiconfesional", principalmente en términos de negociaciones en relación con la decoración y el mobiliario de la sala. En consecuencia, a pesar de los objetivos "modernizadores" del hospital, el peso histórico de la Iglesia católica se hizo rápidamente evidente. Al capellán católico se le asignó el rol legitimado de traducir los requerimientos legales en artefactos concretos para el espacio. Asimismo, se convirtió en la figura de confianza del hospital para delegar las cuestiones religiosas, siempre hasta cierto punto incómodas para la dirección.

El gerente del hospital nos presenta al capellán católico como un miembro del personal del hospital que contribuye al desarrollo de la visión integral de la asistencia sanitaria como experto en cuestiones religiosas. El capellán católico se autodefine como una "persona abierta" y su función asignada es la de desempeñar un papel de mediación entre el obispo católico -considerado como parte de la vieja "guardia católica"- y el equipo directivo del hospital. Sin embargo, a pesar de esta apertura, la política de diseño de la sala multiconfesional después de la firma del acuerdo entre el hospital y el obispo ilustra una historia ligeramente diferente en una doble actitud de resistencia y adaptación de la diversidad en el discurso y la práctica del capellán católico al caracterizar el diseño y la cultura material de la sala.

Aplicando los acuerdos legales, el capellán católico afirmó vehementemente que "cualquier hospital con más de 100 camas debe tener un espacio para orar, una capiIla, por ley" con todos los objetos que esto implica. Mientras que, al mismo tiempo, también explicaba cómo hablaba con la dirección del hospital para cumplir con estos requisitos legales católicos y, a su vez, dar cuenta de la diversidad religiosa aplicando la ley de la manera "más escéptica posible". Con el apoyo financiero del hospital, encargó un altar, unos bancos y un sagrario, móviles, de manera de ser sensible a futuras demandas de diferentes grupos religiosos. Aunque el capellán católico subrayó su frecuente relación con las minorías religiosas en su actividad de capellán parroquial -particularmente con musulmanes y evangélicos que lo invitan en algunas celebraciones importantes- ningún grupo religioso fue invitado ni por parte del capellán ni por parte de la dirección del hospital a participar en la toma de decisiones del diseño y decoración de la sala. De hecho, desde de su creación, la tendencia ha sido que las imágenes y artefactos católicos, aunque móviles, Ilenen cada vez más el espacio. Esta situación ha sido justificada por el capellán como una forma de hacer sentir cómodo al público principalmente católico que visita la sala. Al mismo tiempo, explicaba cómo había intentado difuminar los símbolos religiosos sin dejar de tener en cuenta que la mayoría de la población que utiliza la sala es católica; justificándolo con el ejemplo de la visita del obispo, en la cual una de las prescripciones era tener un sagrario visible, pero él decidió mantenerlo dentro de un armario.

Esta presencia permanente de artefactos católicos que desafían la tendencia neutralizadora de la sala multiconfesional es una forma simbólica a través de la cual el capeIlán católico parece afirmar y mantener algún tipo de propiedad de la sala. Sin embargo, tanto el personal del hospital como el capeIlán católico legitiman esta cultura material del espacio multiconfesional en términos de la neutralidad que representa la movilidad de los objetos católicos. Como subrayaba el directivo del hospital: "hay estas imágenes, pero podrían ser otras; o si hay alguien que no las quiere, estas pueden ser retiradas" (director 
de atención al cliente, caso 1). Asimismo, el capellán católico agregaba que "cualquiera puede venir a orar, siempre está abierto a todos y por tanto todo el mundo puede venir, no hay problema [...] si los musulmanes quieren pedir el uso de la sala, nos ocuparemos de indicar la orientación de La Meca y todas estas cosas" (capellán católico, caso 1).

El resultado actual es que la sala multiconfesional es denominada informalmente por el personal del hospital y el capellán católico como una "capilla", aunque ambos afirman que no es una capilla "normal". El espacio es utilizado principalmente por los servicios católicos semanales a los que asisten personas de la parroquia local, voluntarios de la pastoral católica y, a veces, familiares de pacientes hospitalizados. No obstante, el capellán católico y el personal del hospital también subrayan un uso nuevo y creciente del espacio por motivos de descanso o meditación de personas individuales sin una fe particular.

\section{Caso 2: La creación de un nuevo "nosotros", pero monoteísta}

Este nuevo hospital está situado en una de las ciudades medianas de Cataluña. Al llegar, sin necesidad de pedir información específica, vemos una gran señal en el pasillo de la planta principal que indica "sala multiconfesional". La sala está cerrada. Hay carteles en la puerta con información sobre los servicios católicos y protestantes. Dos miembros del personal del hospital nos invitan a entrar después de una entrevista y nos dicen con orgullo "es muy bonito, ya lo veréis". Contrastando con el caso anterior, la sala, denominada como "oratorio", se presenta como un espacio significativo y con un cierto sentido para el personal del hospital.

La sala responde a un diseño específico y cuidado. Tiene un tamaño mediano, agradable. Las paredes están pintadas de un verde claro, el suelo es de madera y tiene una iluminación cálida. Un cristal colorido, oval a través del cual la luz natural marca la orientación de la sala. También una cruz de mármol y madera, un altar, un sagrario sin imágenes y un atril. Todo aparentemente móvil. Dos cámaras de seguridad vigilan la sala. En el centro hay un espacio con dos filas fijas de sillas de madera y una parte con sillas móviles. Algunas de las sillas tienen folletos y revistas católicas y evangélicas. Al final de la sala, vemos un gran retablo de madera hecho a mano y un pasaje bíblico pintado con un estilo románico. El retablo es susceptible de ser cerrado y tiene pintadas, con hermosas letras en hebreo, árabe, griego, latín, español y catalán: "Génesis 18", "Hospitalidad de Abraham".

Un miembro del personal del hospital nos explica que, cuando se planificó la construcción del nuevo hospital, una de las cosas que el comité de bioética solicitó específicamente fue "un espacio multireligioso con total respeto a todas las personas" (presidenta del comité bioética, caso 2). En este sentido, la presidenta del comité de bioética expresó: "queríamos que se reconociera la dignidad de la gente [...] esta sala representa un espacio específico dirigido a todo tipo de funciones religiosas, celebraciones y rituales" (presidenta del comité bioética, caso 2). El problema fue la conceptualización y el diseño de la sala: "cómo se podía considerar todo cuidadosamente, cómo se podían mantener las necesidades de decoración y de adoración. Pensamos en estos temas para hacerla multiconfesional" (presidenta del comité bioética, caso 2).

Los orígenes históricos del hospital son religiosos y, aunque el hospital comenzó a ser administrado por una corporación no religiosa años después de la Transición Democrática en 1978, el antiguo hospital conservó la capilla católica. El comité de bioética, haciendo referencia a la Ley de Libertad Religiosa de 1980 y a la existencia de una creciente población del hospital religiosamente plural, considero necesario sustituir la antigua capilla por un espacio religioso más "moderno", abierto a la pluralidad. Y, así, explícitamente solicitaron este tipo de espacio al arquitecto del nuevo hospital. El comité articuló la demanda siguiendo las directrices de la política del Gobierno de Cataluña sobre la acomodación de la diversidad religiosa en el ámbito sanitario. El personal del hospital 
destaca cómo el comité de bioética luchó por crear un espacio multireligioso. Lo primero en lo que el comité de bioética trabajó fue en encontrar una iconografía aceptada para todos. Como explica la presidenta: "tomamos un pasaje de la Biblia con el que todos [las diferentes tradiciones religiosas] podían estar de acuerdo; yo no soy muy religiosa y no sé, una monja hizo un hermoso retablo" (presidenta del comité bioética, caso 2). El arquitecto, que tenía formación religiosa, también diseñó cuidadosamente el espacio con símbolos religiosos que pretendían representar la comunión de las tres religiones monoteístas. Por ejemplo, nos explicaban cómo el cristal oval fue diseñado específicamente para tomar la forma de un ábside, con el objetivo de simbolizar la entrada de la luz, la entrada de la divinidad, Dios, aceptado por los hebreos, los cristianos y los musulmanes. Los colores del cristal también tienen un significado religioso, representan los colores del arco iris relacionados con un salmo de la Biblia.

La sala multiconfesional inicialmente cumplió con las expectativas del comité de bioética que escribió un documento oficial para el hospital especificando la naturaleza, los usos y las regulaciones del espacio. Sin embargo, los problemas comenzaron con la Iglesia católica. Después de la inauguración del hospital, el arzobispo reclamó la existencia de un acuerdo entre el hospital y la Iglesia católica. Este convenio, basado en los acuerdos entre el Vaticano y del Estado español de 1976-1979, establecía por ley que la sala destinada a fines religiosos debía tener una "capilla" y que, desde su punto de vista, la capilla debía incluir un altar, un sagrario y algún tipo de bancos para sentarse. El comité de bioética mostró su desacuerdo con relación a las exigencias católicas, ya que poner un altar era algo que no querían, buscaban crear "un espacio muy abierto".

El capellán católico del hospital, tras la inauguración oficial del hospital y según los acuerdos legales reclamados por parte de las autoridades eclesiales, tomó el mando del rediseño de la sala. Nos expresó que los símbolos eran perfectos, pero el espacio no podía quedar vacío: "No había nada, ni siquiera había sillas y, por lo tanto, era neutral, neutral [...] me tomó un año y medio para acomodar el espacio" (capellán católico, caso 2). Así, el capellán relataba que, en lugar de solicitar imágenes de Cristo resucitado o de una Virgen, trató de traducir los mandamientos legales en artefactos móviles que no pudieran herir otras sensibilidades religiosas, respetar a los profesionales del hospital y adaptarse a los objetivos iniciales de una sala respetuosa a múltiples creencias religiosas:

\begin{abstract}
El altar, la mesa del sacrificio, si lo miras, está desnudo para no ofender a los evangélicos [...] todas las cosas excepto el atril tienen ruedas. ¿Y por qué se hizo así? Porque si los evangélicos venían y se sentían incómodos con el altar, lo mantendríamos alejado [...] Las paredes laterales están vacías... pero una parte de la pared, le pedí a uno de mis estudiantes que viniera para indicar dónde estaba La Meca con una piedra. (CapeIlán católico, caso 2)
\end{abstract}

Del mismo modo, especificaba que el sagrario no tenía una cruz en la parte superior como es habitual. Explicaba que estas ideas eran un criterio personal, pero estaban supervisadas por la dirección del hospital que financió esta segunda etapa de la decoración del espacio junto con donaciones de la parroquia local. No obstante, en ningún momento del proceso de diseño y decoración del espacio multireligioso ni el comité de bioética ni el capellán católico hicieron consultas específicas a las minorías religiosas. En realidad, cuando se terminó la decoración del espacio multiconfesional, invitaron a los líderes de las dos principales religiones de la ciudad-evangélicos y musulmanes- pero no asistieron. El capellán católico se quejaba de que, cuando se reunió con los imanes, le agradecieron su atención, pero dijeron que no utilizarían el espacio. Del mismo modo, la pastora evangélica, que ofrecía en el hospital asistencia religiosa desde 2012, expresaba que, aunque utilizan la sala multiconfesional, prefieren la sala polivalente ya que "el retablo es hermoso, no 
quiero crear problemas, pero a pesar de todo esto, todo lo escéptico que pretenden ser, es verdad que marca una tendencia, la marca" (pastora evangélica, caso 2) mencionando el aire católico de la sala. Por otra parte, algunos católicos también se quejaban por la falta de imágenes.

El resultado es que, a pesar de los esfuerzos por crear un espacio abierto a todas las religiones, las demandas no han aumentado en contraste con las expectativas iniciales. La dirección del hospital no entendía, por ejemplo, por qué los musulmanes prefieren orar en las habitaciones privadas del hospital en lugar de usar el espacio multireligioso orientado arquitectónicamente a La Meca. En la actualidad, la sala es principalmente utilizada por la población católica y el personal del hospital, que hablan del espacio multiconfesional en términos de "la capilla", ya que argumentan que, al fin y el cabo, es utilizado principalmente por los católicos. No obstante, los evangélicos también utilizan el espacio para los servicios semanales. Asimismo, como en el caso anterior, observamos una tendencia hacia el uso de la sala como un espacio silencioso y de meditación para los familiares de los pacientes $y$, cada vez más, por parte del personal hospitalario como un "lugar antiestrés", según expresan algunos profesionales.

\section{Caso 3: La multiconfesionalidad como espiritualidad con aires orientales}

Amanda es la responsable de las cuestiones de minorías religiosas en uno de los mayores hospitales catalanes. Empezó a trabajar en el hospital hace veinte años. Al principio trabajó como enfermera en el departamento de psiquiatría, pero hace unos seis años el director del hospital le pidió que se uniera al servicio religioso. Fue contratada como "capellana católica", para que se ocupara también de cuestiones relacionadas con las minorías religiosas. Ella no tenía una formación específica en diversidad religiosa, pero después de asumir esta responsabilidad comenzó a formarse con la ayuda de una asociación interreligiosa de Cataluña.
El hospital recibe fondos públicos, pero está dirigido por una orden religiosa católica. Históricamente, el hospital tenía dos capillas católicas. No obstante, cuando empezó a planificarse una renovación completa de las instalaciones del hospital, Amanda, junto con personal del hospital, propusieron al equipo de dirección que construyera una sala multireligiosa. El director del hospital aceptó la propuesta aunque, a diferencia de los otros casos, la sala multiconfesional no fue concebida como sustitución de la antigua capilla, sino una sala complementaria a la nueva capilla que estaba planificada en el hospital nuevo.

El diseño y el equipamiento de la capilla católica fueron decididos exclusivamente por el sacerdote católico, mientras que Amanda se encargó de la formulación, el diseño y el mobiliario de la sala multiconfesional. Nos explicó que estaba muy emocionada por este desafío pero, al mismo tiempo, no sabía cómo empezar. Decidió solicitar la ayuda y el consejo de la Asociación Interreligiosa Catalana. La asociación ya estaba trabajando en un documento sobre la acomodación de las creencias minoritarias en los hospitales y consideraron que tenía los "conocimientos autorizados" para asesorarlos sobre el tema. La asociación le ofreció a Amanda la posibilidad de contactarse con representantes de minorías religiosas que podrían ayudarla en temas específicos -como marcar la orientación de La Meca- así como proporcionarle algún consejo más general. En este sentido, sugirieron que Amanda no nombrara la habitación como espacio "multiconfesional" -que era su idea inicial- sino que usara un término más genérico como "sala de oración" o "sala de silencio". Optó por esta segunda opción.

En cuanto a la decoración concreta de la sala, Amanda nos explicó que decidió ir a una tienda muy popular que se llama "Natura", donde venden productos de inspiración oriental como almohadas indias, bufandas de seda o taburetes de madera. Ella tuvo la idea de diseñar una habitación con un ambiente cómodo y cálido. Pidió a un representante hinduista que hiciera un dibujo de un mantra 
mientras ella también incluía un ramo de granadas, que es el símbolo del orden. Después de todos estos elementos decorativos, se dio cuenta de que también tenía que incluir "objetos musulmanes" y decidió pedírselos al camarero de Marruecos de la cafetería del hospital. El camarero le dijo que podía encontrar los "objetos necesarios" y compró para ella veinte esterillas y también algunos ejemplares del Corán. La última pieza de los muebles que añadió fue un pequeño banco de madera que fue diseñado por ella y uno de los monjes católicos del hospital y construido por el carpintero del hospital.

La "sala de silencio" se encuentra en la entrada del hospital, cerca del servicio de atención al cliente y al lado de la capilla católica. Actualmente, está siempre abierta, aunque si se cierra en alguna ocasión, todas las personas que quieran usarla pueden pedir la llave en la oficina de recepción del hospital. Amanda, no obstante, se quejó, sorprendida de que la sala no fuera utilizada por los miembros de las minorías religiosas. Hay algunas enfermeras, médicos y otros profesionales que la utilizan para meditar, leer o encontrar un "lugar tranquilo donde descansar". Últimamente, Amanda, junto con un monje católico de la orden que gestiona el hospital han comenzado a organizar sesiones de meditación y otras actividades "espirituales" en la sala silenciosa relacionadas con la espiritualidad oriental tales como prácticas de mindfulness alejadas de la ritualidad y las celebraciones católicas tradicionales como la Eucaristía que se celebra diariamente en la capilla del hospital. Actividades que se han vuelto muy populares en el ámbito hospitalario y que atraen a un número importante de empleados del hospital tal y como explica Amanda: "la mayor parte del personal no es religioso -es decir, católico- pero están realmente predispuestos a participar en actividades espirituales dirigidas a todos" (responsable de servicios religiosos del hospital, caso 3).

Esta "sala de silencio" ha sido tomada como un "caso ejemplar" y es difundida como ejemplo de buenas prácticas por parte de la Asociación Interreligiosa de Cataluña, pero también por parte del Gobierno catalán.
El equipo de administración del hospital se siente orgulloso de la sala y afirma que esto es "un gran recurso que refuerza la reputación del hospital".

\section{DISCUSIÓN}

Los datos empíricos examinados ilustran cómo, a pesar del objetivo formal de crear espacios inclusivos, los resultados de las salas multiconfesionales no son los esperados: las minorías religiosas prefieren orar en otros espacios hospitalarios y los actores católicos se oponen a la sustitución de antiguas capillas por salas multireligiosas a través de diferentes formas de resistencia. Por consiguiente, a pesar de los objetivos conciliadores e integradores de la construcción de salas multiconfesionales, el proceso de creación de un espacio universal y pacífico para todas las religiones y ninguna es una compleja negociación llena de sutiles pero significativas tensiones sobre cómo esta idea de "multiconfesionalidad" debe traducirse en términos materiales y quién debe participar de este proceso de traducción que implica la creación y diseño de este tipo de espacios. Interpretamos el "aparente fracaso" de estas salas como un problema de traducción. La traducción es especialmente difícil ya que implica tres procesos interrelacionados. Por un lado, la traducción del discurso abstracto multireligioso en una dimensión material; por el otro, la traducción de los imaginarios y necesidades prácticas de cada confesión religiosa en un lenguaje "comprensible" para los demás actores religiosos. $Y$, finalmente, también existe un proceso de traducción entre los dominios "religioso" y "secular" para encontrar formas de compatibilizar las dos esferas en el contexto hospitalario.

Podemos argumentar que, en los tres casos explorados, los procesos de traducción se vuelven especialmente difíciles ya que el "acto de traducción" ha sido monopolizado por los actores católicos. Sin cuestionar su buena voluntad, observamos que actúan como "guardianes" del conocimiento 
religioso en las instituciones seculares, adoptando el rol de especialistas. Los actores católicos son capaces de traducir sus propias creencias religiosas en objetos concretos, a la vez que adaptan estos objetos a las exigencias de las autoridades seculares a partir de la introducción, tal y como hemos ilustrado, de la movilidad en los símbolos y artefactos católicos. Al mismo tiempo, actúan como traductores para las otras minorías religiosas, eligiendo los objetos específicos que serán incluidos en estas salas sin contar con estos grupos en el proceso de diseño y creación de los espacios.

Esta traducción, por tanto, está lejos de ser un proceso "neutral" ya que encubre una lucha político-simbólica y una situación de desigualdad de poder que debe considerarse en los procesos de construcción y diseño de este tipo de salas. En el contexto español, los grupos religiosos no parten de las mismas condiciones de posibilidad ni poseen el mismo poder en términos sociales, culturales, políticos y económicos. En el caso de las salas multiconfesionales analizadas, estas desigualdades entre grupos se expresan, principalmente, por la capacidad de los grupos para actuar como traductores o para ser traducidos por otros. Una capacidad que, en el caso de los actores católicos, se acentúa no solo debido a su poder histórico, sino que también se refuerza con el "analfabetismo religioso" ${ }^{\prime(40)}$ del personal del hospital que prefiere delegar su poder a los actores católicos, más que actuar como árbitros del campo religioso. En este sentido, el análisis del proceso de creación de nuevos espacios atentos a la diversidad religiosa muestra el papel crucial de la traducción en imaginar, conceptualizar y diseñar un espacio capaz de satisfacer demandas discordantes y la importancia de encontrar "objetos frontera" (41,42,43) que fomenten la colaboración real entre diferentes grupos religiosos traduciendo sus diferentes concepciones e imaginarios de la religión en una materialidad compartida que, a su vez, no disuelva ni encubra las diferencias religiosas.

\section{CONCLUSIÓN}

La proliferación de los espacios multiconfesionales indica el resurgimiento de la religión en el espacio público y propulsa la discusión sobre los conceptos liberales de neutralidad e igualdad hacia la religión en contextos seculares. Concretamente, el estudio cualitativo de la micropolítica implicada en su formulación, diseño y equipamiento aporta luz sobre la complejidad que envuelve la acomodación de la diversidad religiosa en el ámbito hospitalario. Una complejidad que permanece invisible cuando se trata de acomodar la diversidad religiosa en términos abstractos. Es decir, a nivel discursivo todos los actores parecen coincidir en la importancia de fomentar un enfoque pluralista inclusivo. En el marco del contexto español existe un consenso común sobre la necesidad de superar tanto el histórico monopolio católico sobre los asuntos religiosos como el orden ideológico secularista cuando se enfrentan a los asuntos religiosos en la época contemporánea ${ }^{(44)}$. La modernidad se concibe como un proyecto plural y pluralista por parte de profesionales sanitarios y autoridades religiosas. Este "imaginario plural" se destaca especialmente en el proceso de ideación de nuevas instalaciones hospitalarias diseñadas con el objetivo de satisfacer las necesidades presentes y futuras de los usuarios y este es el motor de la promoción de salas multiconfesionales. Sin embargo, este consenso discursivo se pone en cuestión al traducir el imaginario discursivo en una realidad material compartida. Las divergencias y desigualdades entre actores religiosos se hacen especialmente evidentes en las negociaciones materiales entorno el proceso de ideación, diseño y equipamiento del espacio. En este artículo se evidencia la dimensión conflictual que conlleva la construcción de este tipo de espacios enfatizando la necesidad de considerar estas nuevas salas multiconfesionales en las instituciones públicas como espacios políticos donde las luchas políticas toman forma de luchas simbólicas entre los distintos grupos religiosos. A 
su vez los resultados de este trabajo son relevantes para mostrar que la gestión de los recursos simbólicos involucrados en la política de diseño de los espacios multiconfesionales no necesitan disolver o cubrir las diferencias religiosas sino fomentar la cooperación y, al mismo tiempo, permitir que cada grupo religioso mantenga su propia identidad.

\section{AGRADECIMIENTOS}

La realización de este artículo ha contado con el apoyo y la financiación del proyecto de investigación GEDIVER-IN "La gestión de la diversidad religiosa en centros hospitalarios y penitenciarios en España" (CSO2010-21248) dirigido por el doctor Joan Estruch y la doctora Mar Griera y realizado en el marco del grupo de investigación ISOR, Universitat Autònoma de Barcelona. Queremos agradecer especialmente la colaboración de los hospitales y personas que participaron en esta investigación. También los valiosos comentarios sobre este trabajo de la investigadora Carolina Esteso y de las doctoras Julia MartínezAriño, Gloria García-Romeral y Esther FernándezMostaza.

\section{REFERENCIAS BIBLIOGRÁFICAS}

1. Cadge W. Négocier les différences religieuses dans les organisations laïques: I'exemple des chapelles d'hôpitaux. Social Compass. 2014;61(2):178194.

2. Cadge W. Paging god: religion in the halls of medicine. Chicago: University of Chicago Press; 2012.

3. Campobenedetto D, Giorda M, Robiglio M. The temples and the city: models of religious coexistence in contemporary urban space; the case of Turin. Historia Religionum. 2016;(8):79-95.

4. Crompton A, Hewson C. Designing equality: multi-faith space as social intervention. In: Llewellyn D, Sharma S. Religion, equalities, and inequalities. London: Routledge; 2016. p. 77-88.

5. Gilliat-Ray S. The trouble with "inclusion": a case study of the faith zone at the Millennium Dome. The Sociological Review. 2004;52(4):459-477.
6. Gilliat-Ray S. "Sacralising" sacred space in public institutions: a case study of the prayer space at the millennium dome. Journal of Contemporary Religion. 2010;20(3):357-372.

7. Giumbelli EA. O que é um ambiente laico?: espaços (inter) religiosos em instituições públicas. Cultura y Religión. 2013;7(2):32-47.

8. Holsappel-Brons JC. Space for silence: rooms of silence in the Netherlands - where tradition and transformation meet. Jaarboek voor liturgieonderzoek. 2010;26:221-226.

9. Schützeichel R, Schnabel A. Hochschulen, studierende und religion - soziologische analysen zu aktuellen entwicklungen. Zeitschrift für Beratung und Studium. 2016;11(3):82-85.

10. Crompton A. The architecture of multifaith spaces: God leaves the building. The Journal of Architecture. 2013;18(4):474-496.

11. European Commission Against Racism and Intolerance. General policy recommendation $n^{\circ} 5$ : combating intolerance and discrimination against muslims [Internet]. Strasbourg: Council of Europe; 2000 [citado 27 nov 2017]. Disponible en: https:// tinyurl.com/y7b2q2xj.

12. Gilliat-Ray S. From "chapel" to "prayer room": the production, use, and politics of sacred space in public institutions. Culture and Religion. 2005;6(2):287-308.

13. Bourdieu P. Outline of a theory of practice. Cambrige: Cambridge University Press; 1977.

14. Tilley C. Ethnography and material culture. In: Atkinson P, Coffey A, Delamont S, Lofland J, Lofland L, editors. Handbook of ethnography. London: SAGE; 2001. p. 258-272. 
15. Coffey A, Atkinson P. Encontrar el sentido a los datos cualitativos: estrategias complementarias de investigación. San Vicente del Raspeig: Universidad de Alicante; 2005.

16. Estruch Gibert J. Secularització i pluralisme en la societat catalana d'avui: discurs de recepció de Joan Estruch i Gibert. Barcelona: Institut d'Estudis Catalans; 1996

17. Pérez-Agote A, Santiago García JA. La situación de la religión en España a principios del siglo XXI. Madrid: Centro de Investigaciones Sociológicas; 2005.

18. Pérez-Agote A. El proceso de secularización en la sociedad española. Revista CIDOB d'Afers Internacionals. 2007;(77):65-82.

19. Griera M. Public policies, interfaith associations and religious minorities: a new policy paradigm?; evidence from the case of Barcelona. Social Compass. 2012; 59(4):570-587.

20. Berger PL. The desecularization of the world: resurgent religion and world politics. Grand Rapids: Eerdmans; 1999.

21. Díaz-Salazar R. España laica: ciudadanía plural y convivencia nacional. Madrid: Espasa; 2008.

22. Pérez-Agote A. Cambio religioso en España: los avatares de la secularización. Madrid: Centro de Investigaciones Sociológicas; 2012.

23. Astor A. Religious governance and the accommodation of islam in contemporary Spain. Journal of Ethnic and Migration Studies. 2014; 40(11):1716-1735.

24. Briones Gómez R, Tarrés S, Salguero Ó, Fernández $\mathrm{E}$, Macías $\mathrm{C}$, Suárez $\mathrm{V}$. ¿Y tu (de) quién eres?: minorías religiosas en Andalucía. Barcelona: Icaria; 2010.

25. Díez de Velasco F. The visibilization of religious minorities in Spain. Social Compass. 2010;57(2):235-252.

26. Estruch J, Gómez J, Griera, M, Iglesias A. Las otras religiones: minorías religiosas en Cataluña. Barcelona: Icaria; 2007.

27. Arango, J. Excepcional in Europe?: Spain's experience with immigration and integration [Internet]. Washington DC: Migration Policy Institute; 2013 [citado 1 jul 2017]. Disponible en: https://tinyurl.com/y6u8zr46.

28. Aguilar Fernández S. El movimiento antiabortista en la España del siglo XXI: el protagonismo de los grupos laicos cristianos y su alianza de facto con la Iglesia católica. Revista de Estudios Políticos. 2011;(154):11-39.

29. Casanova J. Public religions in the modern world. Chicago: University of Chicago Press; 1994.

30. Griera M, García-Romeral G, Martínez-Ariño J, Clot-Garrell A. La gestión de la diversidad religiosa en centros hospitalarios y penitenciarios en España [Internet]. Barcelona: Universitat Autònoma de Barcelona; 2015 [citado 1 jul 2017]. Disponible en: https://tinyurl.com/yca3zaqk.

31. Beckford J, Gilliat-Ray S. Religion in prison: "equal rites" in a multi-faith society. Cambridge: Cambridge University Press; 1998.

32. Street A, Coleman S. Introduction: real and imagined spaces. Space and Culture. 2012;15(1):4-17.

33. Díez de Velasco F. Guía técnica para la implementación y gestión de espacios multiconfesionales [Internet]. Madrid: Observatorio del Pluralismo Religioso en España; 2011 [citado 1 jul 2017]. Disponible en: https://tinyurl.com/y9mbeovk.

34. Díez de Velasco F. Multi-belief/multi-faith spaces: theoretical proposals for a neutral and operational design. Augsburg: RECODE Online Working Paper; 2014 [citado 1 jul 2017]. Disponible en: https://tinyurl.com/ybfpodml.

35. Saint-Martin I. La pluralité religieuse à I'hôpital: espaces cultuels et lieux recueillement. In: Lalouette J, Sorrel C. Les lieux de culte en France (1905-2008). París: Letouzey \& Ané; 2008. p. 243-256.

36. Hazard S. The material turn in the study of religion. Religion and Society. 2013;4(1):58-78.

37. Houtman D, Meyer B, editors. Things: religion and the question of materiality. New York: Fordham University Press; 2012.

38. Strijdom J. The material turn in religious studies and the possibility of critique: assessing Chidester's analysis of "the fetish". HTS Teologiese Studies/Theological Studies. 2014;70(1):1-7.

39. Julier G. Urban designscapes and the production of aesthetic consent. Urban Studies. 2005;42(5-6): 869-887.

40. Bramadat $P$, Koenig $M$. International migration and the governance of religious diversity. Ithaca: McGill-Queen's University Press; 2008.

41. Nicolini D, Mengis J, Swan J. Understanding the role of objects in cross-disciplinary collaboration. Organization Science. 2012;23(3):612-629. 
42. Star SL. This is not a boundary object: Reflections on the origin of a concept. Science, Technology \& Human Values. 2010;35(5):601-617.

43. Star SL, Griesemer JR. Institutional ecology, "translations" and boundary objects: amateurs and professionals in Berkeley's Museum of Vertebrate Zoology, 1907-39. Social Studies of Science. 1989;19(3):387-420.
44. Griera M, Martínez-Ariño J, García-Romeral G. Beyond the separation of church and state: explaining the new governance of religious diversity in Spain [Internet]. Göttingen: MPI for the Study of Religious and Ethnic Diversity; 2014 [citado 1 jul 2017]. Disponible en: https://tinyurl.com/yazj9osn.

\section{FORMA DE CITAR}

Clot-Garrell A, Griera M. Las salas multiconfesionales en el contexto hospitalario catalán: negociaciones y tensiones en la gestión de la diversidad. Salud Colectiva. 2018;14(2):289-304. doi: 10.18294/sc.2018.1534.

Recibido: 17 de julio de 2017 | Versión final: 3 de diciembre de 2017 | Aprobado: 28 de diciembre de 2017

Este obra está bajo una licencia de Creative Commons Reconocimiento-NoComercial 4.0

Internacional. Reconocimiento - Permite copiar, distribuir y comunicar públicamente la obra.

A cambio, se debe reconocer y citar al autor original. No Comercial - Esta obra no puede ser

utilizada con finalidades comerciales, a menos que se obtenga el permiso.

http://dx.doi.org/10.18294/sc.2018.1534 